\title{
Visões da posthistoire em Arnold Gehlen e Ernst Jünger
}

[Views on posthistoire in Arnold Gehlen and Ernst Jünger]

http://dx.doi.org/10.11606/1982-88372237158

Sérgio da Mata ${ }^{1}$

Herrn Ernst Jünger:

Wir sind von aussen oft verbunden, wir sind von innen meist getrennt, doch teilen wir den Strom, die Stunden, den Ecce-Zug, den Wahn, die Wunden des, das sich das Jahrhundert nennt.

Gottfried Benn

\begin{abstract}
The article aims to explore the theme of posthistoire in the novel Eumeswil by Ernst Jünger, and in a series of publications made by the sociologist and philosopher Arnold Gehlen. We seek hereupon to emphasize the surprising elective affinities between the two authors, as well as to extract from their writings elements that allow us to shed light on some the dilemmas of our own time.
\end{abstract}

Keywords: Arnold Gehlen; Ernst Jünger; posthistoire, philosophy of history.

Resumo: O artigo busca explorar a temática da posthistoire no romance Eumeswil, de Ernst Jünger, e numa série de publicações do sociólogo e filósofo Arnold Gehlen. Tentamos evidenciar as surpreendentes afinidades eletivas que existem entre os dois autores, assim como extrair de seus escritos elementos que permitam lançar luz sobre alguns dos dilemas de nossa própria época.

Palavras-chave: Arnold Gehlen; Ernst Jünger; posthistoire; filosofia da história.

Dentre os muitos sinais de que o horizonte da modernidade não foi ultrapassado encontrase este: diagnósticos sobre o fim da história continuam a produzir mais irritação que reflexão. Quem ousa levá-los a sério se arrisca, no melhor dos casos, a falar sozinho, e, no pior, a colocar a própria reputação em jogo. Devemos a ninguém menos que Immanuel Kant uma das mais contundentes advertências a esse respeito. "Que possa advir o instante

\footnotetext{
${ }^{1}$ Universidade Federal de Ouro Preto, Rua do Seminário s/n, Mariana, MG, 35430000, Brasil. E-mail: sdmata@ufop.edu.br. ORCID: 0000-0002-7963-6292
}

\section{(c) BY-NC}


em que cessa toda mudança, é uma ideia que escandaliza a imaginação", escreve ele em O fim de todas as coisas (KANT 1971: 334).

Vale ainda a pena nos debruçarmos sobre este tema - ou, quem sabe mesmo, sobre esta ilusão? Pode parecer despropositado recolocar tal pergunta, justamente quando ainda estão frescas na memória imagens que, dentro e fora de nosso país, desautorizam as teses de Francis Fukuyama (1992). A teoria liberal-hegeliana sobre o fim da história se mostrou demasiado otimista, mas está longe de esgotar o acervo de visões a respeito. Metanarrativas como a de Fukuyama estão intimamente ligadas a uma problemática históricofilosófica de fundo, o que justifica o interesse do historiador por elas, não obstante o fôlego curto que possam às vezes revelar. Continua verdadeira, nesse sentido, a conclusão a que chegou Ludwig Landgrebe (1982: 143), de que uma filosofia da história que pretenda atingir um grau máximo de reflexividade não pode se dar ao luxo de ignorar o problema do fim da história. A questão não parece ser menos relevante para o estudioso da literatura. Caso George Steiner esteja com a razão quando afirma que "literatura é expectativa dramatizada", de pronto se revelam as implicações estéticas do problema da pós-história. Atingido este ponto-limite, pergunta-se ele (STEINER 1988a: 327), “o que viria a substituir o mecanismo primordial da esperança frustrada?"

Mais do que tentar decifrar o mistério da historicidade, a reflexão sobre o histórico bem pode servir-se de pontos de vista situados (ou que busquem se situar) "fora" do histórico, descrevendo um esforço que nem sempre foi perseguido de forma consequente. Análogo à moral provisória cartesiana ou à epoché fenomenológica, tal esforço pode ser considerado uma espécie de simulação sem a qual não se chega a um entendimento mais profundo das coisas. A capacidade de produzir em si mesmo esse estranhamento do olhar é a premissa de toda verdadeira compreensão: ohne Befremdung kein Verständnis (PLESSNER 2000: 170). Ao longo do século XX e a partir de motivações as mais diversas, o alheamento do histórico se deu, em geral, por meio de um anseio de "reabilitação" do mito. Uma saída do histórico, portanto, em busca daquilo que o antecede. Mais escasso foi o número dos que optaram pelo caminho oposto, os que pensaram o histórico a partir daquilo que presumidamente o sucederia. Ao colocar lado a lado os escritos de dois autores que raramente costumam ser associados entre si, Ernst Jünger e Arnold Gehlen, acreditamos encontrar elementos que permitam lançar alguma luz sobre o problema da posthistoire - cuja absurdidade, em que pesem as reprimendas de Kant, talvez seja apenas aparente. 
Num momento em que, por toda a parte, as democracias ocidentais estão submetidas a stress tests que supúnhamos improváveis até bem pouco tempo, parece útil avaliar mais de perto como certa análise cultural conservadora elaborou sua perspectiva sobre a pós-história. Qual é o horizonte próprio desta visão de mundo, e o que podemos aprender com ela - sim, aprender - a fim de promover avanços justamente quando eles dão a impressão de exigir o dobro, o triplo, de nossa energia?

Dada a dificuldade de se definir o conservadorismo em termos substantivos, e não apenas porque a filiação de Jünger a esta tradição está longe de ser um ponto pacífico, o mais indicado é identificar o pensamento conservador a partir das disposições temporais que o caracterizam. Se nos fiarmos na análise já clássica de Karl Mannheim, o mais próprio do pensamento conservador é a sua tendência a "experimentar os acontecimentos [presentes - SM] em termos de uma atitude derivada de circunstâncias e situações ancoradas no passado", e, o que não chega a ser contraditório, a contemplação da história menos como uma ordem de sucessões que como um feixe de simultaneidades (MANNHEIM 1986: 123, 126).

Haveria muito o que dizer sobre a história do conceito de pós-história, a respeito do qual se discutiu intensamente a partir de fins da década de 1980 (MEIER-OESER 1989; Niethammer 1989; Steenblock 1994; Mehring 1996; Flusser 1997). A despeito do interesse que possa ter para nós um exercício de história conceitual, a proposta aqui é que possamos nos deter sobre a questão da forma mais sóbria e concisa possível. Evidentemente, as implicações teóricas, estéticas e políticas da tese da posthistoire só poderão ser esboçadas. Uma delas pode ser formulada nos seguintes termos: caso se possa de fato ultrapassar o umbral da história, numa derradeira Zeitschwelle, então a objetividade, que acreditávamos expulsa do horizonte do historiador, volta a se colocar como uma possibilidade. Não mais como um imperativo moral ou uma virtude epistemológica, fique claro, mas como uma possibilidade.

Apesar de a literatura acadêmica não ignorar completamente as aproximações entre Gehlen e Jünger, parece ter faltado quem lhes desse um tratamento mais cuidadoso. Desde logo, há que reconhecer que a associação que aqui se promove entre eles nada tem de óbvia. Se o primeiro é autor mundialmente conhecido, o mesmo está longe de valer para o segundo. ${ }^{2}$ Embora os dois tenham ganhado projeção entre os anos 1920 e 1940,

\footnotetext{
${ }^{2}$ Gehlen continua pouco conhecido fora da Alemanha. Além das vetustas traduções para o português de $A$ alma na era da técnica e Moral e hipermoral, só recentemente apareceram versões do seu artigo sobre a
} 
inclusive preservando-a após o advento da segunda democracia alemã, não há registro de que tenham mantido relações entre si. Jünger não incluiu Gehlen entre os seus parceiros filosóficos preferenciais, e é quase certo que Gehlen via em Gottfried Benn, e não no autor de Tempestades de aço o grande escritor alemão do pós-guerra. Ademais, Gehlen morreu um ano antes da publicação do romance de Jünger de que falaremos a seguir. Como justificar, então, nosso esforço de aproximação?

Não o faremos pela via daqueles (KuZMiCs; MozeTIČ 2003) que veem na literatura um manancial de exempla postos à disposição da análise sociológica; e muito menos daqueles que gostariam de ampliar o arsenal categorial da crítica literária às custas da sociologia do pós-histórico. Prevalecesse uma das duas opções, um campo seria colocado numa situação subsidiária, e um autor "a serviço" do outro. A intenção, muito mais modesta, consiste em identificar um rol de homologias que nos parecem compor uma imagem coerente, situada a meio termo entre o ficcional e o real, mas que justamente em épocas de crise dá a impressão de tornar-se ainda mais sedutora. São as expressões paroxísticas de um fenômeno que Odo Marquard (1983: 495) acredita ser moderno por excelência. Fenômeno próprio de uma época que "transforma a realidade num campo de testes (Wirksamkeitsfeld) de ficções", e em que "princípio de realidade e princípio ficcional se fundem".

\section{II}

Foi justamente quando, à base de um pensamento apocalíptico-revolucionário (SCHNETTLER 2004: 233), as ações armadas do grupo Baader-Meinhof ameaçavam abalar as estruturas da República Federal, que Ernst Jünger pintou em Eumeswil um quadro sombrio e perturbador de um mundo sem história, em que o historiador Manuel Venator reflete longamente sobre a natureza do poder político e de sua própria profissão. ${ }^{3}$ Pouco antes de Jünger dar os retoques finais em seu livro, Gehlen havia refinado seu diagnóstico, não menos perturbador, da entrada do gênero humano na posthistoire. Ao abordá-los conjuntamente, tentaremos evidenciar a complementaridade existente entre o discurso literário e a descrição sociológica produzidos por estes dois importantes intelectuais alemães do século XX. Eles nos fornecerão elementos para enriquecer a descrição da 
entropia temporal que caracteriza a nossa época (MATA 2018), ou, quando menos, a que vem se desenhando há alguns anos em nosso país, sob a forma de uma crise terminal do sistema político.

É compreensível que um importante aspecto de Eumeswil praticamente não tenha merecido a atenção dos críticos e filósofos que escreveram a seu respeito, mas tal não pode ser o nosso caso: Manuel Venator, o protagonista de Jünger, é um historiador, e um historiador que nasce numa família de historiadores. Ao invés de dedicar-se exclusivamente à erudição, ele toma a decisão de trabalhar também, no período noturno, como um prosaico barman. Não se trata, contudo, de um bar qualquer, e sim do que existe na corte do Condor, tirano da cidade-estado de Eumeswil. Enquanto tenta entender, a partir de dentro, o funcionamento do poder político, Manuel se perde em pensamentos sobre sua vida, sobre a política, sobre os historiadores e sobre a história - ou antes, a póshistória.

Qual é o tempo próprio deste "romance pós-histórico" (RUBEL 2000: 764)? ${ }^{4}$ Curiosamente, trata-se de um tempo moderno na sua acepção plena, marcado pela coexistência de distintos regimes temporais e pela simultaneidade do não-simultâneo (NASSEHI 2008). Visões distópicas são construídas a partir de motivos retirados à Antiguidade, provenientes, sobretudo, da civilização helênica. Indicações esparsas no texto permitem situar a narrativa num futuro distante, em algum momento após o início do terceiro milênio depois de Cristo. A intensa homogeneização econômica, política e cultural de inícios do século XXI, época do "Estado Mundial”, posteriormente deu lugar a um processo de desagregação ao fim do qual restaram apenas "os reinos dos diádocos e as cidades-Estado dos epígonos" (JÜNGER 1987: 213, 277, 447). ${ }^{5}$ Na geografia mítica de Jünger, Eumeswil situa-se às margens do Mediterrâneo, em um lugar não muito bem definido entre Cartago e Jerusalém. Sua integridade territorial é mantida graças à aliança com o Cã Amarelo, líder de uma grande potência do norte. Salvo pela presença de

\footnotetext{
${ }^{4}$ A opinião de Renner (2014: 252) de que Eumeswil seria um romance pós-moderno não nos parece convincente, e não apenas por omitir o fato de que Jünger se distanciou do conceito de pós-modernidade (PEKAR 2012: 199). O erro, como cedo sublinhou Johannes Weiss (1993), está em confundir os conceitos de posthistoire e pós-modernidade.

${ }^{5}$ Como se sabe, o conceito de Estado mundial remonta à obra de seu amigo Carl Schmitt. Jünger sistematiza suas posições a respeito em Der Weltstaat, ensaio no qual postula que a grande disputa travada entre Ocidente e Oriente na Guerra Fria era meramente ilusória. Os impérios norte-americano e soviético partilhariam os mesmos conceitos políticos fundamentais (paz, liberdade, democracia), o mesmo culto da técnica, até mesmo o mesmo símbolo da estrela. Num platonismo que antecipa claramente a atual crítica de setores reacionários ao "globalismo", Jünger via nos dois grandes blocos as "duas metades da mesma fôrma do Estado mundial" (JÜNGER 1960: 24).
} 
avançada tecnologia, tudo ali evoca a situação de instabilidade e lenta decomposição do Império Macedônio de meados do século IV a.c.. A propósito, Eumeswil deve seu nome a Eumênio, um dos auxiliares mais próximos de Alexandre o Grande, e que se tornou sátrapa da Capadócia após a morte do grande conquistador. O poder, obtido pela força das armas, é exercido com mãos de ferro pelo Condor, um misto de déspota esclarecido e tirano (JÜNGER 1987: 14, 59). A situação política é sempre tensa. O regime tem de se haver com inimigos dispostos em três frentes: os simpatizantes do antigo regime - quando vigorava um modelo descentralizado, controlado pelos tribunos - uma débil oposição (a respeito da qual se costuma fazer vistas grossas), e a oposição clandestina radical, formada por anarquistas e guerrilheiros.

No livro não há propriamente um enredo, mesmo porque em Eumeswil, como sabemos, já não há história. Em sua biografia de Jünger, Kiesel (2007: 636) sugere que o ritmo modorrento da narrativa deixa perceber em si mesmo a inércia em que está enredado esse estranho mundo pós-histórico. Com o espírito meticuloso de um ornitólogo, Manuel acompanha o dia a dia da corte: retém na memória fragmentos de diálogos do Condor, decifra a personalidade de seus auxiliares mais próximos como o Domo e Átila, constrói uma extensa série de analogias históricas. Interessa-lhe o mecanismo de funcionamento daquela estrutura de poder, similar à do período dos diádocos macedônios e dos tiranos renascentistas. Na distopia de Jünger nada indica que a jaula de ferro da dominação possa ser quebrada. Quando muito, a tirania é substituída pela oligarquia, até que outro aventureiro a ponha abaixo. Para Manuel, "matar o tirano seria como cortar a cabeça da hidra; para cada tirano morto surgiriam trinta" (JÜNGER 1987: 293).

Por um gosto de paradoxo ou simples ironia, Jünger faz de um historiador o protagonista de uma história que se passa num mundo pós-histórico. De fato, soa improvável para o leitor a riqueza do pensamento de Manuel, um jovem de 29 anos. Mas isso importa pouco. Àquela altura com 82 anos de idade, Jünger se sentiu confortável para vestir a pele do historiador, o qual, diferentemente do soldado - a famosa advertência foi feita por Ranke - precisa ser velho. Por outro lado, muito do talento precoce de Manuel se deve ao fato de que ele pertence a uma estirpe de historiadores. Um de seus antepassados, Josiah Venator, escrevera importante obra intitulada Felipe e Alexandre. Do pai e do irmão, também eles historiadores, dois "liberais típicos" e nostálgicos da época dos tribunos, ele fala com desprezo (JÜNGER 1987: 22, 47). 


\section{DA MATA, S. - Visões da posthistoire}

Seus verdadeiros "pais espirituais" são Vigo, Bruno e Thofern. Em Vigo, historiador de quem se torna assistente na universidade, Manuel admira o profundo senso de individualidade, a aversão às modas acadêmicas, a imperturbável objetividade, o método morfológico e a visão trágica da tarefa do historiador. Aproxima-os ainda um interesse comum pelas épocas de decadência. Avesso a "sortilégios", Vigo encara seu trabalho com uma "tristeza fundamental" (JÜNGER 1987: 24, 100). O filósofo Bruno, de quem Manuel frequentou o curso sobre história do ceticismo, é um mestre cuja exposição "irradia racionalidade". ${ }^{6}$ A despeito de sua grande familiaridade com a história das ideias, Bruno "era capaz de apagar a consciência histórica e suas paixões" (JÜNGER 1987: 70, 76). Thofern, o linguista, seduz menos pela atitude ou pelo método que pelo seu tema: o processo de decadência da linguagem, entendido como expressão de uma "época agonizante" e da "perda da história" (JÜNGER 1987: 97-99). ${ }^{7}$ Enquanto Bruno se refugia em seu ceticismo, Thofern e Vigo sofrem a perda da linguagem e do passado. A dor de Thofern é "a de um homem inspirado, numa época sem inspiração" (JÜNGER 1987: 104). A de Vigo advém de sua luta inglória contra o esquecimento. Quando é bem-sucedido, o historiador "vence o tempo e triunfa sobre a morte" (JÜNGER 1987: 97). De tal sorte que está diante de ruínas cuja reconstrução sempre ultrapassa a medida de suas forças. A dor é o torrão do historiador. "Mal pegamos a pena", diz Manuel, e "a tortura começa" (JÜNGER 1987: 193). Esta dor, "ele a sente com especial agudeza quando reflete sobre o destino dos reformadores do mundo. Um lamento sem fim, uma eterna esperança se transmite de geração em geração, como tocha que vez por outra se apaga" (JÜNGER 1987: 369).

Esperança é uma palavra vã num lugar como Eumeswil, descrito por Vigo como a "inundação de uma massa a-histórica e inculta sobre uma base alexandrina", e que para Manuel não passa de um "estado de felás" (JÜNGER 1987: 32, 229). ${ }^{8}$ Uma sociedade sob todos os aspectos decadente, "periodicamente explorada por demagogos no aspecto

\footnotetext{
${ }^{6}$ De fato, o contato crescente do mundo grego com outras culturas teria levado, em fins do Império Macedônio, ao surgimento de um "ceticismo pleno de consequências" (DilTHEY 1960: 3).

${ }^{7}$ Dada a escassez de bons estudos sobre Eumeswil, é difícil saber se Jünger se deixou inspirar por alguém neste particular. Salta aos olhos, em todo o caso, a similitude entre as posições de Thofern e as de George Steiner (1988b: 30-54) em seu notável ensaio "O repúdio à palavra", de 1961.

${ }^{8}$ Objeto de diversos estudos, a importância de Oswald Spengler para Jünger parece confirmada pelo uso recorrente do termo "felá" em Eumeswil. No vocabulário spengleriano, Fellachenvölker são os povos que vivem a-historicamente, imersos num planloses Geschehen: muita coisa acontece, mas nada de significativo (SPENGLER 1922: 204).
} 
moral, até que chegam os generais e lhes põem uma coluna vertebral protética" (JÜNGER 1987: 289).

O jovem historiador se limita a constatar que "a história está morta", e que vive num "mundo de epígonos" onde o progresso cessou e "a agitação interior faz os acontecimentos se moverem em círculo”. Há ainda alguma dinâmica social e política, mas não história propriamente. "O catálogo das possibilidades parece esgotado", e as revoluções, tendo se tornado crônicas, evidentemente "não mudaram nada". A "substância histórica" consumiu-se, e "o corpo social, como um peregrino cansado da longa caminhada, entrega-se ao descanso". Ao historiador resta constatar como a lógica da superação é substituída pela da repetição. Manuel é perseguido pela frase de Bruno, de que "sobre a parede cujo reboco se desprendia voltariam a reaparecer os ídolos há muito esquecidos" (JÜNGER 1987: 223, 339, 86, 114, 71).

É a visão de um intelectual. Será a das massas? Manuel afirma que em Eumeswil “a massa é a-histórica, [e] a elite meta-histórica" (JÜNGER 1987: 340). O povo "não quer um futuro melhor; quer viver bem agora. Não quer ouvir o tilintar das moedas, quer têlas no bolso" (JÜNGER 1987: 87). A mudança não é considerada positiva em si mesma, pois "o homem vulgar se sente satisfeito quando sua vida segue um ritmo constante; gosta de ver a fumaça da chaminé, não o incêndio de sua casa" (JÜNGER 1987: 223). Mesmo estudantes de história, antigos colegas de Manuel na faculdade, não contradizem essa tendência geral. $\mathrm{O}$ fascínio de Vigo pelo passado lhes parece antiquado, posto que para eles “o fundamental é o instante presente” (JÜNGER 1987: 32). A musa da história deve amargar sua sorte num mundo em que "até os meninos riam dos deuses" (JÜNGER 1987: 102-103).

Em nosso intento de descrever Eumeswil em suas grandes linhas, quase nos esquecemos que Manuel se põe a serviço de um tirano. Talvez possamos desculpá-lo porque ele não o faz na condição de intelectual, do intelectual típico, cuja vontade de poder é muitas vezes análoga à do soberano. Tal como no modelo do cientista "puro", Manuel obedece apenas aos ditames da própria curiositas. Seu trabalho noturno é um posto avançado de observação, onde registra tudo o que lhe parece relevante. É o entendimento das leis do mecanismo que o interessa, não sua posse. Nesse sentido, podese dizer que ele serve ao Condor, mas não ao poder. Do ponto de vista teórico, Manuel vê a si mesmo como um meta-historiador e um "cético", um "positivista" inspirado por Vigo e pela figura arquetípica de São Tomé (JüNGER 1987: 86, 141, 250). Pode-se 
questionar, a partir das sugestivas notas de Hans Blumenberg, se por detrás da metahistória de Jünger/Manuel, com sua predileção pelas analogias e sua aversão pelo concreto, não se revela um estilo de pensamento platonizante (BLUMENBERG 2010: 34, 144). Mas, ainda aqui, temos a nítida impressão de que não se trata da rotineira construção de um personagem literário. Se entre os professores evocados na primeira parte do romance Jünger tivesse incluído alguém familiarizado com a sociologia do conhecimento, este provavelmente diria que a possibilidade da objetividade histórica, em Eumeswil, é um efeito colateral do esgotamento do histórico. ${ }^{9}$ Como assim?

Manuel acredita que Eumeswil "oferece ao historiador uma situação especialmente favorável, pois aqui não existe nenhum tipo de valores. [...] Não há crença nas ideias, e causam estranheza as vítimas sacrificadas em outras épocas em razão de suas convicções" (JÜNGER 1987: 59). As antigas crenças liberais, que ainda moviam seu pai e seu irmão, não passavam agora, diz ele, de simples "paródias" (JÜNGER 1987: 62). Nos tempos passados houve quem considerasse a objetividade como a qualidade distintiva dos eunucos entre os historiadores. Atingido um estágio como o descrito por Daniel Bell em The End of Ideology (BELL 1980), o que acontece é que "à força de serem repetidas, as grandes ideias se desgastaram. Já ninguém move um dedo por elas" (JÜNGER 1987: 86). ${ }^{10}$ A imparcialidade não é mais que um autoengano, como quem sabe possa ter sido na época que o livro caracteriza como dos "Estados combatentes", mas a atitude epistêmica natural tão logo a chama da paixão política se extingue. Manuel conclui: “as grandes ideias brotam no coração, disse um francês antigo. Poder-se-ia acrescentar: e são frustradas pelo mundo" (JÜNGER 1987: 82; JÜNGER 1993: 70).

Em face de tudo isso e a partir das lições de seus mestres, ele elabora sua própria posição e se define como um "anarca". Dada a simultaneidade do aparecimento do livro e o auge do terrorismo de esquerda no famoso “outubro alemão" de 1977, é compreensível que se tenha dado especial atenção à doutrina do anarca nos primeiros estudos publicados sobre Eumeswil. Digamos apenas que para Jünger o anarca nada tem comum com o anarquista. Enquanto o anarca coloca sua liberdade individual - sobretudo de consciência - acima de todas as coisas e, em decorrência disso, se torna um ser solitário, o anarquista

\footnotetext{
${ }^{9}$ Tal ideia fora claramente antecipada em An der Zeitmauer (JÜNGER 1959: 94-95).

${ }^{10}$ Bell se queixou das incompreensões produzidas pelo título de seu livro, um conjunto de ensaios no qual, a bem da verdade, a expressão "fïm da ideologia" sequer aparece. Para ele, tal como para Jünger e Gehlen, a noção de "fím" não deve ser entendida em sentido literal, mas da maneira indicada pelo subtítulo de sua coletânea: On the exaustion of political ideas in the Fifties. A respeito, ver o interessante balanço de Brick (2013).
} 
é um gregário incorrigível, movido por um idealismo confuso, anacrônico. Em Eumeswil há dois tipos de anarquista, o "benigno" e o "maligno". Os primeiros não fazem mal a uma mosca, mas mesmo os últimos não passam de perigosos úteis, cujo gosto pela violência mais reforça os mecanismos de dominação que os abala. Se o anarquista radical sonha em aniquilar o soberano, o anarca não vê problema no convívio com este: o único domínio a que almeja é o domínio de si. Daí que Manuel se coloque "em uma relação objetiva e também cética em face do poder" (JÜNGER 1987: 50, 363, 365). "Tenho a firme determinação", declara ele, "de não me comprometer com nada, não aceitar coisa alguma com seriedade definitiva" (JÜNGER 1987: 103). Num outro trecho, Manuel diz não se sentir vinculado nem "ao presente político nem à tradição; sou uma folha em branco, aberta e capacitada a todas as direções" (JÜNGER 1987: 293). Manuel acredita que todo historiador é, até certo ponto, um anarca; e que "caso tenha estatura suficiente, a partir desta base se converte em juiz imparcial" (JÜNGER 1987: 50-51). Tal objetividade, como vimos, não resulta de escolhas epistemológicas ou éticas. Ela é, por assim dizer, a consequência necessária quando nenhuma das opções disponíveis satisfaz. O compromisso maior do historiador-anarca não é, como entre os antigos gregos, com o conhecimento ou com o legado deixado às gerações futuras, mas com a sua liberdade individual. Mais do que o anarquista, ele está apto a captar o elemento anárquico, a "força primitiva" que todo ser humano, até mesmo toda realidade, carrega em si: "o amor é anárquico, o matrimônio não. O guerreiro é anárquico, o soldado não. O homicida é anárquico, o assassino não. Cristo é anárquico, Paulo não" (JÜNGER 1987: 48). E como para Manuel "a história universal se move mediante a anarquia" (JÜNGER 1987: 49), talvez fosse o caso de acrescentar: a história é anárquica, a historiografia não.

No entanto, este elemento disruptivo perdeu a sua força, aquietou-se. Algo como "uma espécie de corte transversal paralisador [...] seciona o nervo da história", destino a que está condenada Eumeswil "ainda que passem mil anos". Todas as tentativas de reverter este estado de coisas, conclui ele, "são mais fantásticas que epigônicas". A póshistória se resume a uma sucessão de "grandes períodos vazios, sem sangue e sem saque" (JÜNGER 1987: 171). Por toda a parte o que se vê é "o esgotamento, o pântano lodoso. (...) O mundo se torna insignificante. A palavra perde substância, sobretudo ali onde deve ser algo mais do que simples comunicação" (JÜNGER 1987: 83). 
Temos agora de nos deslocar para a antessala da literatura, e retornar ao húmus de onde ela brota e que a torna possível, a realidade. Acessando a obra de Gehlen, percebe-se em que medida sua sociologia oferece elementos para a leitura não apenas de Eumeswil, mas também daquilo que se passa ante nossos próprios olhos. E embora tenha havido quem apostasse na tese de que o escritor tenha sido influenciado pelo sociólogo (KRON 1998: 13), as evidências a respeito não parecem convincentes. Jünger e Gehlen eram Zeit-, não Gesinnungsgenossen. Eis o que torna ainda mais interessante o fato de que ambos tenham recorrido ao período do helenismo. Em 1969, ao empreender sua vigorosa crítica à hipertrofia moral das sociedades industriais, Gehlen se detém longamente na figura de um contemporâneo de Eumênio: o filósofo estoico Zenão de Cítio (340-264 a.c.). Da mesma maneira que Droysen, Gehlen vê no helenismo uma época marcada pelo declínio cultural e pela concomitante ascensão de uma intelectualidade moralista, alheia (ao menos no plano do discurso) à realidade demoníaca do exercício do poder. ${ }^{11}$ Tal moralismo, como a arte helênica, não passava de um conjunto de formas destituídas de conteúdo: expressão mais característica de "uma das épocas mais mentirosas da história" (GEHLEN 1984: 31). Mas as aproximações entre Jünger e Gehlen dizem menos respeito ao que possa haver de comum entre Manuel Venator e Zenão, do que àquilo que ambos parecem simbolizar à luz de seus respectivos contextos: a relação que existiria entre crescente prestígio dos intelectuais e perda de vitalidade cultural. No que diz respeito a seus usos do passado, pode-se dizer que a diferença fundamental a ser sublinhada é que para Jünger o helenismo é metáfora, e para Gehlen, prefiguração.

Falamos em usos do passado. Seria possível falar em usos da ficção pela sociologia da posthistoire? Há indícios de sobra nesse sentido, todavia eles não apontam na direção de Jünger. É antes para Gottfried Benn que temos de nos voltar, uma vez que sua presença nos ensaios e livros de Gehlen se atesta sem grande esforço. Não é improvável, aliás, que ao se definir como um "comentarista da ruína" (apud REHBERG 2013: 102), Gehlen estivesse apenas dando um sinal a mais disso. São recorrentes suas menções ao grande poeta, e recentemente ficou demonstrado que a admiração entre os dois era recíproca (DUTT 2016: 375-375). Pouco antes de morrer, Gehlen escreve que em

\footnotetext{
${ }^{11}$ A "era dos diádocos" foi chamada por Droysen de a "Idade Média do mundo greco-asiático". Para o grande historiador, neste período a tradição retórica grega evanescia, a poesia dava lugar à emulação, a religião à teocracia e a política à mediocridade (DROYSEN 1836: vi, 8).
} 
Der Ptolemäer se manifesta "o alto lamento nostálgico da consciência do fim da civilização ocidental" (GEHLEN 2017: 148). Com efeito, nesta novela de 1949 Benn proclamara a "ausência de futuro" (Zukunftslosigkeit) e o "fím do dogma" do homo sapiens. Não chegou, é verdade, a falar em fim da história; seu raciocínio é mais complexo: “Certamente ainda existiriam épocas, históricas, por assim dizer. Tão sem ruído e melodia este réptil, a 'História', não se esquivou” (BENN 1980a: 185). ${ }^{12}$ Somente na década seguinte Jünger elaboraria um ponto de vista parecido. Ele se perguntava se a humanidade teria chegado a um estágio em que os eventos não estariam mais "articulados de uma forma a que nos habituamos chamar de história, mas de uma outra, que não chegamos ainda a nomear" (JÜNGER 1959: 94). ${ }^{13}$ Seria iminente o "adeus à história" (JÜNGER 1959: 111).

Ainda não nos é possível dizer em que medida a sociologia da pós-história de Gehlen foi estimulada pelo contexto literário de inícios da Era Adenauer, embora saibamos que ele atuou por algum tempo como coeditor da Wiener Literarisches Echo, onde publicou uma resenha das Strahlungen de Jünger (STREIM 2008: 145). Em todo o caso, é certo que o estímulo decisivo não veio daí. Como fez questão de ressaltar várias vezes, sua adoção do conceito de posthistoire se deu a partir da leitura do livro Vermassung und Kulturverfall: Eine Diagnose unserer Zeit, publicado em 1951 pelo belga Hendrik de Man. É de se supor que, a partir daquele momento, o que era um sentimento vago de toda uma geração tenha subitamente adquirido, para Gehlen, um fundamento sólido - tanto por estar lastreado numa tradição científica respeitável, quanto por oferecer uma alternativa à visão cíclica de Spengler, que, como se sabe, gozava da simpatia de Jünger.

A quintessência do argumento de De Man se encontra nesta passagem:

Contemporâneos de grande sensibilidade, nos quais a consciência desta situação [atual $\mathrm{SM}$ ] provoca vertigens, interpretam-na como se tivéssemos passado a uma época que não pertence mais à história. Até onde alcança meu conhecimento, o francês Bertrand de Jouvenel foi o primeiro a dar expressão a tal pensamento. Com isso ele não queria dizer

\footnotetext{
${ }^{12} \mathrm{Na}$ Alemanha da segunda metade da década de 1940 difundiu-se de forma impressionante a semântica do "fim", como atestam os exemplos de Alfred Weber e Karl Jaspers ("fim da história"), Romano Guardini ("fim da era moderna") e Josef Pieper ("fim do tempo"). O retorno deste fenômeno nos anos 1990 sugere que ao menos duas premissas devem ser consideradas: de um lado, a resiliência da concepção judaico-cristã da história universal; e, de outro, a experiência de grandes traumas históricos. A respeito, deve ser consultado o denso estudo de Gerd Irrlitz (1996).

${ }^{13}$ Temos a sensação de reencontrar aqui as palavras de Guardini, dadas a público em 1950. Para este influente filósofo católico, era hora de se "reconhecer o fim da Idade Moderna e a nova época que se aproxima, e que ainda não foi designada pela história" (GUARDINI 2000: 50). No original: von der Historie noch nicht benannten Epoche.
} 
o mesmo que outro francês, o matemático A. A. Cournot, que cunhou, há um século, a expressão post-histoire; já que com ela Cournot pretendia designar a situação que advém quando uma criação ou instituição humana qualquer é a tal ponto aperfeiçoada que toda transformação morfológica ulterior fica de antemão excluída. A perspicaz teoria de Cournot, que desde então não recebeu a merecida atenção, [...] permite, aplicada ao momento atual, fundamentar a conclusão de que nossa civilização preencheu seu sentido "arquetípico" e, por conseguinte, entrou numa fase destituída de sentido; a alternativa, do ponto de vista biológico, não seria nem morte nem mutação. Aquilo que Spengler vê como um ser ahistórico difere inteiramente do que Jouvenel e Cournot têm em mente. Não se trata, na post-histoire, da letargia de uma civilização cuja força vital se esgotou, mas da entrada numa fase dos eventos mundiais (Weltgeschehen) que ultrapassa completamente os quadros da história, uma vez que as conexões historicamente determináveis entre causas e efeitos deixam de existir. É da essência da ciência histórica reconhecer e descrever, em sua conexão de sentido, os acontecimentos que estruturam o devir da humanidade. Mas se os eventos em si mesmos se mostram destituídos de sentido, então a história atinge o seu limiar. (DE MAN 1952: 124-125)

Tudo leva a crer que não foi pequeno o entusiasmo de Gehlen ao ler a passagem acima e se familiarizar com o conceito criado por Cournot. Tanto é que se apropria dele imediatamente, empregando-o em dois artigos de 1952. Talvez por não ter ainda amadurecido suas próprias análises a respeito, suas primeiras menções à pós-história são feitas quase que à margem destes textos. A intuição dispunha agora de uma armadura conceitual; faltava dotá-la de conteúdo: “Teremos já saído da história e adentrado a posthistoire?" (GEHLEN 1963a: 246) "Se for este o caso", observa ele, "naturalmente não se poderá mais dizer rigorosamente nada sobre o futuro". Caso contrário, "então ainda é possível extrair do passado consequências para o futuro" (GEHLEN 1978: 19).

Há dois elementos centrais na análise de Cournot e De Man. O primeiro diz respeito ao longo processo por meio do qual a história universal aos poucos revela seu sem-sentido, tema do notável livro de 1949 de Karl Löwith, Meaning in History. A morfologia da condição pós-histórica é o passo subsequente, ao qual Gehlen dedica uma série de escritos. Daí a ironia feita em seu último livro, publicado no rescaldo do 1968 alemão: "quem já não quer obedecer mais aos humanos cede pelo menos ainda a um deus. Hoje esse deus é a história" (GeHLEN 1984: 19). Na esteira de Tucídides, Burckhardt, Huizinga, Scheler e Plessner, para Gehlen a condição humana se situa aquém e além do tempo histórico. ${ }^{14}$

Mas não separemos o homem de seu contexto. A literatura do Entre-guerras mostra que a ascensão do conceito de historicidade nunca deixou de suscitar certa desconfiança. Em 1927 - mesmo ano em que aparecia a obra mais conhecida daquele a

\footnotetext{
${ }^{14}$ Também para Jünger (1960: 36-37), “enquanto espécie, o ser humano marcha ileso em meio ao declínio de gerações, povos e culturas".
}

Pandaemonium, São Paulo, v. 22, n. 37, mai.-ago. 2019, p. 158-181 
quem Gehlen se referia como “o yogi de Freiburg” (apud REHBERG 2013: 94) -, Kurt Tucholsky escrevia o seguinte:

Acredito na história porque as variações que jogam com a humanidade não são tão numerosas. Tudo retorna ao menos uma vez - sempre. Os motivos, as paixões, as relações entre mulher e homem - sim, até mesmo as formas em que isso acontece são incessantemente retiradas ao mesmo grande armário. É um caleidoscópio - há ali um grande número de nuances, é verdade, mas as pedrinhas são sempre as mesmas. (TUCHOLSKY 1975: 263) $)^{15}$

À sua maneira, Tucholsky antecipa o que Gehlen chamou, num influente ensaio de 1961, de "cristalização cultural", ${ }^{16}$ no qual o insight de Cournot e De Man seria desenvolvido de forma consequente. A segunda metade do século passado teria assinalado o esgotamento dos grandes sistemas de ideias, das grandes visões de mundo surgidas no século XIX. Tais sistemas, alguns deles obra de um só homem (Freud, Marx, Nietzsche), decerto continuam a existir, mas apenas como um "modelo vazio". Hoje não há espaço sequer para sucedâneos: trata-se de algo que "não está mais dentro das possibilidades de nossa época". Depois de duas guerras mundiais, só têm futuro aquelas doutrinas capazes de manter em movimento as engrenagens das modernas sociedades industriais (GEHLEN 1963b: 316). Enquanto a virada civilizacional entre 1750 e $1850 \mathrm{deu}$ início a uma era das grandes singularizações, as nossas sociedades se mostram cada vez menos aptas a trabalhar com meta-linguagens. A experiência que predomina é a da pluralização. Cada comunidade de sentido elabora um cosmos semântico próprio, que permanece pouco permeável (quando não fechado) para os demais (BERGER; LUCKMANN 2004; SNOw 2016). A centralidade de que passa a gozar a ciência em nossa civilização amplia e aprofunda este processo de babelização do mundo. O mesmo pode ser constatado no âmbito das artes plásticas, em que há muito a obra de arte se emancipou do grande público e abdica de qualquer esforço de representação de territórios que ultrapassem a estrita subjetividade do artista. Para Gehlen, até mesmo o conceito de vanguarda perde sua força, soa ultrapassado. "Quem fala hoje de vanguardismo", conclui, "fala de liberdade de movimento enquanto programa" (GEHLEN 1963b: 322).

\footnotetext{
${ }^{15}$ Mas tarde a mesma metáfora seria retomada por Blumenberg, referindo-se ao plano das trajetórias individuais: "A vida não é nem uma nuvem nem um rio, mas um caleidoscópio. Quando dizemos que [ela - SM] acaba por um esgotamento não nos referimos a nenhuma forma de cansaço e esvaziamento, mas sim a um esgotamento das possibilidades" (BLUMENBERG 2010: 212).

${ }^{16}$ É pouco provável que o conceito tenha sido cunhado pelo próprio Gehlen. Em seu Post-Historic Man, de 1950, o norte-americano Roderick Seidenberg falou de um "universal process of crystallization" advindo do domínio da máquina sobre o homem, até que os indivíduos "will remain encased in an endless routine and sequence of events" (apud MEIER-OESER 1989: 1140). Não nos foi possível saber se Gehlen teve acesso ao livro de Seidenberg.
} 
Cristalização é o termo que designa uma situação em que as possibilidades de um sistema cultural por assim dizer se esgotam, ainda que o corpo social possa ser dotado de intensa dinâmica interna. As "novidades" que eventualmente despontam no horizonte haurem o seu material de um reservatório cujos elementos já se encontram previamente à disposição (GEHLEN 1963b: 321). Não há propriamente criação, mas, no máximo, bricolagem. Em 1967, Gehlen enfim apresenta uma definição mais precisa deste processo: o conceito de cristalização "significa que diminui a probabilidade de transformações substanciais nos fundamentos da civilização, embora aumente ou possa perfeitamente aumentar o número e o ritmo das variações superficiais" possíveis (GEHLEN 2004: 333). Atinge-se um ponto em que "nada mais se deve esperar da história das ideias". O horizonte se fecha à nossa frente, e eis que "chegamos à posthistoire" (GEHLEN 1963b: 322-323). Nenhuma nova ideologia há de surgir, "nenhum evento inesperado e de grande importância poderá acontecer". Convém observar que o mais característico da posthistoire é a Überraschungslosigkeit, a "ausência de surpresas" (GEHLEN 1963b: 323; GEHLEN 1975: 123), não a lentidão. Caso tivesse vivido um ano a mais, o suficiente para presenciar o aparecimento de Eumeswil, Gehlen decerto concordaria com Jünger quanto à progressiva "transformação do efêmero em sacramento" (JÜNGER 1987: 118). Também em sua sociologia da arte ele discutiu as implicações deste processo:

Nossas livrarias ainda dispõem da mesma literatura, como a dos anos vinte; os museus, dos mesmos quadros - e, contudo, falta o essencial: a força com que tudo aquilo foi vivido. [...] De tudo isso advém uma importante novidade: de agora em diante não haverá mais nenhum desenvolvimento artístico imanente! A história da arte imbuída de algum sentido lógico imanente acabou, o desenvolvimento chegou a seu termo, e o que há de vir já existe: o sincretismo da confusão de todos os estilos e possibilidades, a posthistoire. (GEHLEN 2016: 292-293) ${ }^{17}$

A crescente agitação política das décadas de 1960 e 1970 não levou Gehlen a rever seu diagnóstico. Num momento marcado pela grande influência do neo-marxismo frankfurtiano, mas também pela emergência de uma crítica cultural de cariz conservador nos Estados Unidos, representada por Daniel Bell, George Steiner e Christopher Lasch, Gehlen dedicaria ainda dois ensaios à sua fenomenologia da pós-história.

Ele vê a Europa como um continente "esgotado" (GEHLEN 1975: 125), e mesmo em áreas como a matemática e a física as grandes descobertas teriam cessado. A ciência histórica avança, sem, porém, expressar uma consciência histórica subjacente (GEHLEN 2004: 353). Em flagrante contraste com a experiência dos séculos XVII e XVIII, na pós-

${ }^{17} \mathrm{O}$ grifo é do próprio Gehlen.

Pandaemonium, São Paulo, v. 22, n. 37, mai.-ago. 2019, p. 158-181 
história a própria filosofia se torna completamente inofensiva à ordem instituída (GEHLEN 2004: 357). Na mesma proporção do gradativo empobrecimento da linguagem, aumenta também "a tendência aos argumentos moralizadores", uma vez que sua finalidade precípua é "encurtar o processo de comunicação" (GEHLEN 1984: 182).

O máximo a que podemos aspirar é a "pequena história", isto é: "movimentação sobre uma base estacionária" (GEHLEN 1975: 122).

Entre as características mais importantes deste processo, Gehlen enumera as seguintes: (a) grandes eventos políticos só ocorrerão por meio da reconfiguração de alternativas que já se encontram à nossa disposição; (b) as bases da sociedade técnicoindustrial se tornaram definitivas; (c) em vão esperaremos por algum novo grande apelo capaz de suscitar nosso entusiasmo e disposição para a luta (GEHLEN 1975: 125). Em suma: "Nenhuma crença louca, magnífica, nenhum horizonte aberto, nenhuma fata morgana, nenhuma utopia de tirar o fôlego, mas apenas o mero transcorrer, as tarefas do dia" (GEHLEN 1975: 126). Teremos de conduzir nossas vidas entre o "conformismo crescente das massas" e a "intolerância face aos dissidentes" (GEHLEN 1975: 131). ${ }^{18}$

\section{IV}

Como procuramos demonstrar, há inúmeras convergências entre as narrativas literária e sociológica da pós-história. Quanto às diferenças, não menos evidentes, elas podem ser resumidas em poucas palavras. Mesmo que Gehlen e Jünger possam ser considerados representantes da chamada "crise do historicismo" dos anos 1930-1940, sem dúvida estamos diante de olhares inteiramente diferentes, e mesmo opostos, sobre o caminho que leva à posthistoire.

Admitamos: bem pode ser que tudo isso não passe de uma vertigem do histórico. E, no entanto, a tese da posthistoire faz sentido. E faz sentido, como percebeu Hans Freyer em sua Teoria da época atual, precisamente numa civilização que eleva o histórico à condição de sacramento (FREYER 1965: 189, 214-215). Não será consequente, nos termos deste estilo de pensamento, que aquilo que em dado momento passou a definir as sociedades modernas possa também estar sujeito a um processo de erosão? Ou perguntar-

\footnotetext{
${ }^{18}$ Impossível subscrever a interpretação de Tolone, para o qual a posthistoire, em Gehlen, corresponderia a la fine del senso (TOLONE 2007: 413). "Sentido" não é uma categoria transcendental para Gehlen, nem desempenha papel de relevo em sua obra.
} 
se, como Löwith (1949: 207): “Como se pode imaginar a história como um processo contínuo dentro de uma progressão linear, sem pressupor um terminus a quo e ad quem descontínuo, isto é, sem um princípio e um fim?” Para o pensamento mítico tal situação é inconcebível, pois nele o movimento, embora circular, nunca chega a seu termo. Justamente aqui nos deparamos com o que há de problemático na visão de Jünger. Que o ser humano possa recorrer ao mito como forma de se esquivar desta vertigem, mostra-o a vitalidade de que ainda hoje gozam os mitos políticos em contextos de modernidade periférica. Em nosso próprio país, ora é a uma espécie de neo-sebastianismo, ora é à eterna luta entre Leviatã e Behemoth que parecemos estar condenados. Em sua busca desesperada por sentido, a saída da história pela via do mito é uma tentativa de responder a uma pergunta: se o primado do histórico deve conduzir, no limite, à saída do histórico, não será o caso de abdicar da decisão do espírito humano que, num passado distante, nos legou este fardo? A nostalgia do mito que se manifesta nas biografias escritas no círculo de Stefan George, na teologia política de Carl Schmitt e na ciência das religiões de Mircea Eliade advém do mesmo impulso básico, qual seja, o desejo de se "voltar àquela irresponsabilidade arcaica de entregar-se, sem mais, a poderes que não podem ser contrariados" (BLuMENBERG 2003: 17). Duas gerações de intelectuais europeus, de Georges Sorel aos autores da Dialética do esclarecimento, viram no mito o dispositivo cultural capaz de compensar a Belastung da História. ${ }^{19}$ Em consonância com tais tendências, Jünger, depois de tomar conhecimento da obra de Eliade, imediatamente manifesta o desejo de criar uma revista em parceria com o erudito romeno. O projeto se concretiza em 1959, com a publicação do primeiro número de Antaios (PSCHERA 2007).

Gehlen tinha uma visão mais resignada das coisas, assentada em sua teoria do humano como um "ser de carências" (GEHLEN 1955). Toda a frágil estabilidade com que o homem pode contar nessa vida é a proporcionada por instituições, entendidas no sentido radicalmente amplo que ele emprestava ao termo. Para um autor que se definia como um

\footnotetext{
${ }^{19}$ Eliade escreve em 1949 que graças ao "ponto de vista [mítico - SM], dezenas de milhões de homens, século após século, foram capazes de suportar enormes pressões históricas sem se desesperar, sem cometer o suicídio nem cair naquela aridez espiritual que sempre traz consigo uma visão relativista ou niilista da história" (ELIADE 1992: 130). Não menos problemática que esta visão do mito enquanto pharmakon, é a subordinação da análise do mito à crítica do esclarecimento em Adorno e Horkheimer. Daí que a cabal descontinuidade entre mito e filosofia do Iluminismo no plano das suas respectivas disposições temporais seja, no geral, silenciada em seu livro. Se chegam a fazer menções incidentais à "renovação infinita", ao "movimento cíclico" e à "renúncia à esperança" no mito (ADORNO; HORKHEIMER 2006: 23, 33), é porque postulam, à base da suposta continuidade entre um e outro, que o esclarecimento seria tão "conservador" quanto o seu antecessor histórico. Não muito tempo depois tal tese seria definitivamente refutada por Löwith (1949) e Koselleck (1999).
} 
DA MATA, S. - Visões da posthistoire

"filósofo empírico", ${ }^{20}$ a busca dos arquétipos e do eterno retorno em plena era da técnica certamente tinha algo de quimérica. Podemos imaginar que ele subscreveria o juízo de Blumenberg, para quem o olhar platonizante de Jünger expressava uma tendência a "desvalorizar a normalidade da existência como sua inautenticidade ontológica" (BLUMENBERG 2010: 36, 144, 197). Resta claro, na perspectiva da antropologia filosófica, que um projeto como o de Jünger só se poderia realizar no plano das imagens e símbolos, jamais no mundo da vida. Sua fuga do histórico era antes uma fuga "para trás", e, paradoxalmente, deixava trair a esperança de que uma grande reforma cultural seria ainda possível; possibilidade que Gehlen, Plessner, Löwith e Blumenberg viam com justificado ceticismo.

A fim de deixar mais claras as diferenças em questão, convém contrapor, mais uma vez, Jünger a Benn. Se para um "parece que sistemas cíclicos são mais adequados ao espírito" (JÜNGER 1959: 75), o outro percebe as coisas de outra forma: Nicht Entwicklung, Unaufhörlichkeit wird das Menschheitsgefühl des kommenden Jahrhunderts sein (BENN 1980b: 290). Não desenvolvimento, mas movimento incessante há de ser o sentimento da humanidade do século XXI. Daí a convicção de Gehlen de que na pós-história o que se tem é a apenas a "pequena história" (GEHLEN 2017: 151). Movimentação, decerto, mas sobre uma base estacionária. Caso adotemos um approach fenomenológico, colocando momentaneamente entre parênteses a nossa própria consciência histórica - a qual é determinada culturalmente, não ontologicamente (LUCKMANN 2002) -, as perspectivas de Benn e Gehlen se mostram consequentes justamente nos termos de uma visão histórica de mundo. Sua premissa é que a saída do histórico deva se dar a jusante, não a montante do fluxo temporal. Estamos falando de um esgotamento, não de uma consumação quiliástica do histórico.

O recurso ao mito enquanto grande terapêutica universal é o que explica porque Jünger não é capaz de captar, em toda a sua radicalidade, o problema da simultaneidade do não-simultâneo na modernidade. Rapidamente nos damos conta de como o "pântano lodoso" da cidade-estado de Eumeswil, não obstante sua interessante mescla de motivos antigos e modernos, ganha ares de exemplaridade. Ao passo que Gehlen está atento às ressurgências, ou antes, à possibilidade de que "povos ainda não consumidos pela história" se disponham a subir ao altar de Clio no momento mesmo em que outros dele

\footnotetext{
${ }^{20}$ Daí a aversão de Gehlen a um tratamento filosófico convencional, in abstracto, da questão. É o caso, por exemplo, do já aludido ensaio de Landgrebe (1982).
}

Pandaemonium, São Paulo, v. 22, n. 37, mai.-ago. 2019, p. 158-181 
se apartam. Colocando sob nova luz a temática da Spätzeit, sugere ele, seria possível apreender os fenômenos do nosso tempo "como uma espécie de interferência ou interpenetração recíproca de um período civilizacional de estilo antigo com uma época inteiramente nova" (GEHLEN 1961: 88).

A título de conclusão, sejam-nos permitidas ainda algumas palavras a respeito do problema da posthistoire. Nossa curiosidade a respeito não poderia ter sido desinteressada, e o leitor, é claro, sabe disso. Façamos então a pergunta que ele espera de nós: em que medida parte desse diagnóstico pode ser projetado na situação brasileira atual, cujos contornos básicos começaram a se delinear em junho de 2013 ? O que temos diante de nós é história pra valer, ou tudo não passa de "pequena história"?

A leitura mais realista, a que estamos pessoalmente inclinados, tem pouco em comum com a dos que insistem em ver em toda crise a possibilidade de advento do novo. Quando tudo é platitude, ou bem se foge para o interior da floresta, como decide enfim fazer o herói trágico de Eumeswil, ou se assume resignadamente a lição que Gehlen extrai de suas considerações sobre os grandes historiadores da Antiguidade: Man muss oben stehen, um etwas zu sehen (GEHLEN 1975: 117). Diríamos que aqui se expressa, com a clareza cristalina de um tipo ideal, a situação de alguns dos mais controvertidos intelectuais na Alemanha do pós-guerra. Não raro, o passado nacional-socialista era expiado através de um exílio interno, cujo paradoxal resultado, ao longo das décadas seguintes, foi a transformação de lugares incógnitos como Plettenberg (Schmitt), Wilflingen (Jünger), Todtnauberg (Heidegger) e Speyer (Gehlen) em verdadeiros centros de peregrinação. Talvez isso ajude a entender por que, bem antes da escrita de seu romance, Jünger dizia ver na cidade o avesso da liberdade: “A liberdade física, espiritual e ética é incompatível com o seu ar", razão pela qual os homens verdadeiramente livres e sábios "buscavam os desertos e as velhas cavernas nas montanhas" (JÜNGER 1960: 67). Nessa quase antecipação do destino de Manuel Venator, havia também uma tentativa de inverter simbolicamente, e não sem boa dose de auto-encenação, a antiga máxima medieval: Stadtluft macht frei.

Há razões para acreditar que não se trata aqui, apenas, de uma crítica de Jünger e Gehlen à situação e ao modelo político da República Federal, e de que que Eumeswil é sem dúvida uma extravagante alegoria. Jacob Taubes, cujo entusiasmo pelo maio de 1968 
é bem conhecido, não estava substancialmente afastado dessa crítica. ${ }^{21}$ Mas evoquemos ainda um último exemplo, menos conhecido. Em 1977, uma ex-militante do Partido Comunista Brasileiro Revolucionário, Nancy Mangabeira Unger, publica no exílio um texto de rara beleza, do qual extraímos estas breves passagens:

O que caracteriza o momento histórico que agora vivemos é a instalação insistente, insidiosa, angustiante, da dúvida e da perplexidade. [...] Houve um eclipse. [...] É noite sendo dia, ou melhor, não se sabe o que é noite e o que é dia. Não há orientação possível. Não há como medir o tempo. [...] A pergunta volta, insidiosa, torturante: e se não for de um eclipse que se trata? E se o sol tiver desaparecido no grande definitivo daquilo que nunca existiu? (UNGER 2000: 21-22)

Se tais palavras expressam um sentimento a que muitos hoje se sentem novamente inclinados, de pronto se evidencia, ao fim destas breves notas sobre a pós-história, o que há de anacrônico em todo o pathos existencialista. A questão demanda uma outra abordagem, orientada menos pela ontologia que pelas ciências da realidade.

É comum dizermos que a história não se repete, mas raramente se ressalta que isso vale, em especial, para sociedades cujos membros desenvolveram uma consciência histórica em termos plenos. O que dizer, porém, de uma sociedade como a nossa, na qual este processo dá reiteradas mostras de não ter deitado raízes? E mais, na qual os grupos que deveriam constituir a base social e o ponto de irradiação de uma visão histórica de mundo volta e meia sucumbem ante a confortável e sedutora dança dos arquétipos? Se no Brasil, como sugeriu Vilém Flusser, a consciência histórica tem se revelado sobretudo como "consciência da impotência" (FLUSSER 1997: 199-200), os motivos bem podem residir no fato de que em determinadas civilizações este gênio da lâmpada, a consciência histórica, eventualmente se apresenta na forma de uma "falsa consciência" (MATA 2015: 213-214). Portanto, como “ideologia”, e no sentido mais próprio do termo. Inútil evocar este espírito quando a lâmpada está vazia.

Se esta peculiaridade se relaciona com a recente leva de tragédias - culturais, políticas, ambientais - que nos tem assolado, é uma hipótese a considerar. Num de seus mais instigantes ensaios, Löwith nos lembra que os eventos históricos podem prescindir da consciência histórica pelo simples fato de que ocorrem ainda que os ignoremos; mas

\footnotetext{
${ }^{21}$ É digno de nota que Agamben tenha dedicado seu livro O tempo que resta a Taubes. Em 1968, era compreensível que este erudito notável julgasse, num ensaio recheado de menções a Gehlen, que "ainda não saímos da história nem chegamos à post-histoire" (TAUBES 1969: 134). Em seus últimos anos, articulando Schmitt e Gehlen, Taubes muda de posição, empregando inclusive - como Gehlen em 1976 (GEHLEN 2017: 148) - o conceito de época "Biedermeier" como um signo de a-historicidade: "The Biedermeier days of our post-histoire... in which a lot happens but nothing takes place anymore" (apud MARTIN 2017: 149); "Wir leben in einer Biedermeierei" (TAUBES 1987: 54).
} 
que dispor de uma consciência histórica abre a possibilidade de co-determinar o rumo dos acontecimentos (LÖWITH 1983: 421). Mas onde tal consciência está ausente, como na primeira alternativa aventada, que configuração a "história" tende a assumir ali? Não o sabemos, mas pressentimos: nela o ser humano não aparece na condição de agente, mas na de vítima. Logo, a "história" já não se apresenta como uma sucessão de feitos, res gestae, mas de tragédias. Restará constatar a aporia constitutiva sobre a qual estaria assentada a cultura brasileira, tensionada entre seu inegável déficit de consciência histórica e a realidade de uma época cujas estruturas parecem estar apontando na direção da gradativa obsolescência daquilo que sequer logramos conquistar.

Mas nem tudo é perda; bem pode ser que haja ganhos. O mais importante deles é a perda de plausibilidade das visões utópicas. É justamente naqueles lugares em que os seres humanos enfim se dão conta - para usar a bela imagem de Robert Spaemann - de que "as árvores não crescem até o céu”" (SPAEMANN 2002: 11) que o desejo de fazer deste mundo um lugar melhor adquire exequibilidade. Mas há também ganhos de outro tipo, puramente epistemológicos. O lento desvanecer da utopia permitiria aos historiadores recuperar algo do senso de objetividade que moveu os grandes nomes da nossa disciplina no passado. Como insistiu Max Weber, essa tarefa infinita, a de tentar apreender e descrever o mundo como ele é (WEBER 2014: 463), só pode ser considerada quimérica pelos que abdicaram de todo senso de responsabilidade política e intelectual. Por caminhos e razões diferentes, é verdade, em sua maturidade Gehlen e Jünger evitaram o perigoso jogo dos extremos que os seduzira a certa altura da vida.

Maturidade significa, ao menos para nós: atingir aquele senso mínimo de realidade que E. P. Thompson (1981) pedia a todo verdadeiro historiador, e, por conseguinte, dispor-se senão a rever, pelo menos a matizar os próprios diagnósticos: a última palavra não deve ser dada à “teoria”. Gehlen (2004: 360) era suficientemente sagaz para conceder que "tal como antes, surpresas ainda são possíveis". E Jünger, que não o era menos, admite que "não pode ter morrido aquilo que deu conteúdo à história e a pôs em marcha". Pois "vivemos sobre uma camada fóssil que pode, de repente, começar a cuspir fogo" (JÜNGER 1987: 399).

\section{Referências bibliográficas}

AdORnO, Theodor W.; HoRKHEIMER, Max. Dialektik der Aufklärung. Frankfurt am Main: Fischer, 2006.

Pandaemonium, São Paulo, v. 22, n. 37, mai.-ago. 2019, p. 158-181 
BELL, Daniel. O fim da ideologia. Brasília: UnB, 1980.

BENN, Gottfried. Der Ptolemäer. Berliner Novelle, 1947. In: BENN, Gottfried. Das Hauptwerk, Bd 3. Wiesbaden: Limes, 1980a, p. 171-223.

. Die neue literarische Saison. In: 1980b, p. 279-290.

. Das Hauptwerk, Bd 2. Wiesbaden: Limes,

BERGER, Peter; LUCKMANN, Thomas. Modernidade, pluralismo e crises de sentido. A orientação do homem moderno. Petrópolis: Vozes, 2004.

BLUMENBERG, Hans. Trabajo sobre el mito. Barcelona: Paidós, 2003. El hombre de la luna. Sobre Ernst Jünger. Valencia: Pre-Textos, 2010.

BricK, Howard. The End of Ideology Thesis. In: FreEdEN, Michael; SERGEANT, Lyman T.; STEARS, Marc (eds.) The Oxford Handbook of Political Ideas. Oxford: Oxford University Press, 2013, p. 90-112.

DE MAN, Hendrik. Vermassung und Kulturverfall: Eine Diagnose unserer Zeit. München: Leo Lehnen, 1952.

DILTHEY, Wilhelm. Weltanschauungslehre, Leipzig: B. G. Teubner, 1960.

DROYSEN, Johann Gustav. Geschichte des Hellenismus. Erster Theil. Hamburg: Friedrich Perthes, 1836.

DutT, Carsten. Arnold Gehlen. In: HANNA, Christian M.; REENTS, Friederike (Hrsg). Benn Handbuch. Leben - Werk - Wirkung. Stuttgart: J. B. Metzler, 2016, p. 374-375.

EliADE, Mircea. Mito do eterno retorno. São Paulo: Mercuryo, 1992.

FLUSSER, Vilém. Nachgeschichte. Eine korrigierte Geschichtsschreibung. Frankfurt am Main: Fischer, 1997.

FREYeR, Hans. Teoria da época atual. Rio de Janeiro: Zahar, 1965.

FuKUYAMA, Francis. The End of History and the Last Man. New York: The Free Press, 1992.

GEHLEN, Arnold. Der Mensch. Seine Natur und seine Stellung in der Welt. Bonn: Athenäum, 1955.

. Die Seele im technischen Zeitalter. Sozialpsychologische Probleme in der industriellen Gesellschaft. Hamburg: Rowohlt, 1961.

. Über die Geburt der Freiheit aus der Entfremdung. In: GEHLEN, Arnold. Studien zur Anthropologie und Soziologie. Neuwied: Luchterhand, 1963a, p. 232-246.

. Über kulturelle Kristallisation. In: GEHLEN, Arnold. Studien zur Anthropologie und Soziologie. Neuwied: Luchterhand, 1963b, p. 311-328.

. Ende der Geschichte? In: GEHLEN, Arnold. Einblicke. Frankfurt am Main: Klostermann, 1975, p. 115-133.

. Die Rolle des Lebensstardards in der heutigen Gesellschaft. In: GEHLEN, Arnold. Gesamtausgabe, Bd 7, Frankfurt am Main: Klostermann, 1978, p. 15-19.

. Moral e hipermoral. Rio de Janeiro: Tempo Brasileiro, 1984.

. Post-Histoire. In: GEHLEN, Arnold. Gesamtausgabe, Bd 6. Frankfurt am Main: Klostermann, 2004, p. 352-361.

Zeit-Bilder. Zur Soziologie und Ästhetik der modernen Malarei. In: GEHLEN, Arnold. Gesamtausgabe, Bd 9. Frankfurt am Main: Klostermann, 2016, p. 1-332.

. A felicidade evadida. Uma interpretação da nostalgia. História da Historiografia, v. 10, n. 23, 2017, p. 142-152.

GUARDINI, Romano. O fim da Idade Moderna. Lisboa: Edições 70, 2000.

IRRLITZ, Gerd. Die wesentliche Täuschung vom Ende. In: STIERLE, Karlheinz; WARNING, Rainer (Hrsg.) Das Ende: Figuren einer Denkform. München: Wilhelm Fink, 1996, p. 330-358.

JÜNGER, Ernst. An der Zeitmauer. Stuttgart: Klett-Cotta, 1959.

. Der Weltstaat. Organismus und Organisation. Stuttgart: Klett-Cotta, 1960.

Eumeswil. Rio de Janeiro: Guanabara, 1987.

. Eumeswil. New York: Marsilio Publishers, 1993.

Pandaemonium, São Paulo, v. 22, n. 37, mai.-ago. 2019, p. 158-181 
KANT, Immanuel. Das Ende aller Dinge. In: KANT, Immanuel. Abhandlungen nach 1781. Akademie Textausgabe Band VIII. Berlin: Walter de Gruyter, 1971, p. 325-339.

KIESEL, Helmuth. Ernst Jünger. Die Biographie. München: Siedler, 2007.

KOSELLECK, Reinhart. Crítica e crise. Uma contribuição à patogênese do mundo burguês. Rio de Janeiro: Contraponto/EdUERJ, 1999.

KRON, Jürgen. Seismographie der Moderne. Modernität und Postmodernität in Ernst Jüngers Schriften von 'In Stahlgewittern' bis 'Eumeswil'. Frankfurt am Main/Berlin/Bern/New York/Paris/Wien: Peter Lang, 1998.

KuZMICS, Helmut; MozeTIČ, Gerald. Literatur als Soziologie. Zum Verhältnis von literarischer und gesellschaftlicher Wirklichkeit. Konstanz: UVK, 2003.

LANDGREBE, Ludwig. Das philosophische Problem des Endes der Geschichte. In: LANDGREBE, Ludwig. Faktizität und Individuation. Studien zu den Grundfragen der Phänomenologie. Hamburg: Felix Meiner, 1982, p. 137-156.

LöwITH, Karl. Meaning in History. The Theological Implications of the Philosophy of History. Chicago: The University of Chicago Press, 1949.

Geschichte und historisches Bewußtsein. In: LÖWITH, Karl. Weltgeschichte und Heilsgeschehen. Zur Kritik der Geschichtsphilosophie. Stuttgart: J. B. Metzlersche Verlagsbuchhandlung, 1983, p. 411-432.

LUCKMANN, Thomas. Lebensweltliche Zeitkategorien, Zeitstrukturen des Alltags und der Ort des „historischen Bewusstseins”. In: LUCKMANN, Thomas. Wissen und Gesellschaft. Ausgewählte Aufsätze 1981-2002. Konstanz: UVK, 2002, 55-66.

MANNHEIM, Karl. O pensamento conservador. In: MARTins, José de Souza (ed.) Introdução crítica à sociologia rural. São Paulo: Hucitec, 1986, p. 77-131.

MARQUARD, Odo. Das Fiktive als ens realissimum. In: HENRICH, Dieter; IsER, Wolfgang (Hrsg.) Funktionen des Fiktiven. Wilhelm Fink: München, 1983, p. 489-495.

MARTIN, Jamie. Liberalism and History after the Second World War: The Case of Jacob Taubes. Modern Intellectual History, v. 14, n. 1, 2017, p. 131-152.

MATA, Sérgio da. Geschichts-Intellektuelle in der Krise. Das Unbehagen in der heutigen brasilianischen Geschichtswissenschaft. In: GRAF, Friedrich W.; HANKE, Edith; PICHT, Barbara (Hrsg.) Geschichte intellektuell: Theoriegeschichtliche Perspektiven. Tübingen: Mohr Siebeck, 2015, p. 202-215.

. Entropia temporal: das razões sociológicas aos limites antropológicos. In: SALOMON, Marlon (org.) Heterocronias: estudos sobre a multiplicidade dos tempos históricos. Goiânia: Ricochete, 2018, p. 226-257.

MEHRING, Reinhard. Karl Löwith, Carl Schmitt, Jacob Taubes und das „Ende der Geschichte“. Zeitschrift für Religions- und Geistesgeschichte, v. 48, n. 3, 1996, p. 231-248.

MeIER-Oeser, Stephan. Posthistoire. In: RITTER, Joachim; GrÜNDER, Karlfried; GabrIEL, Gottfried. Historisches Wörterbuch der Philosophie, Bd. 7. Basel: Schwabe, 1989, p. 1140-1141.

NASSEHI, Armin. Die Zeit der Gesellschaft. Auf dem Weg zu einer soziologischen Theorie der Zeit. Wiesbaden: VS Verlag für Sozialwissenschaften, 2008.

Niethammer, Lutz. Some afterthoughts on posthistoire. History and Memory, v. 1, n. 1, 1989, p. 27-53.

PEKAR, Thomas. Vom Nationalen zum planetarischen Denken. Brüche, Wandlungen und Kontinuitäten bei Ernst Jünger. In: ScHÖNING, Matthias; STÖCKMANN, Ingo (Hrsg.) Ernst Jünger und die Bundesrepublik. Ästhetik - Politik - Zeitgeschichte. Berlin: De Gruyter, 2012, p. 185-204.

PlesSNER, Helmuth. Mit anderen Augen. Aspekte einer philosophischen Anthropologie. Stuttgart: Reclam, 2000.

PSCHERA, Alexander. Heilige Tiefe und geistiger Überblick: die Zeitschrift Antaios (1959-1971). Sezession, v. 16, 2007, p. 18-23. 
REHBERG, Karl-Siegbert. Arnold Gehlen als Briefschreiber. Zeitschrift für Ideengeschichte, v. 7, n. 3, 2013, p. 93-108.

RENNER, Rolf G. Eumeswil. In: Schöning, Matthias (Hrsg.) Ernst Jünger Handbuch. Leben Werk - Wirkung. Stuttgart: Metzler, 2014, p. 250-257.

RochA, Clarissa Marinho. Literatura e antropologia: a tradução parcial de 'O ser humano' de Arnold Gehlen. Dissertação de Mestrado. UFF, Niterói, 2016.

RUBEL, Alexander. Venator historiae. Der Historiker als „subtiler Jäger”. Geschichtsphilosophisches in Ernst Jüngers Eumeswil. Études Germaniques, v. 55, 2000, 763-780.

SNOw, Charles Percy. As duas culturas e uma segunda leitura. São Paulo: Edusp, 2016.

SpaEmanN, Robert. Grenzen. Zur ethischen Dimension des Handelns. Stuttgart: Klett-Cotta, 2002.

SPENGLER, Oswald. Der Untergang des Abendlandes, 2. Bd. München: C. H. Beck, 1922.

SCHNETTLER, Bernt. Zukunftsvisionen. Transzendenzerfahrung und Alltagswelt. Konstanz: UVK, 2004.

STEINER, George. Literatura e pós-história. In: STEINER, George. Linguagem e silêncio. São Paulo: Cia das Letras, 1988a, p. 326-337. . O repúdio à palavra. In: STEINER, George. Linguagem e silêncio. São Paulo: Cia das Letras, 1988b, p. 30-54.

STEENBLOCK, Volker. Das „Ende der Geschichte”: Zur Karriere von Begriff und Denkvorstellung im 20. Jahrhundert. Archiv für Begriffsgeschichte, v. 37, 1994, p. 333-351.

STREIM, Gregor. Das Ende des Anthropozentrismus. Anthropologie und Geschichtskritik in der deutschen Literatur zwischen 1930 und 1950. Berlin: Walter de Gruyter, 2008.

TAUBES, Jacob. Kultur und Ideologie. In: AdORNO, Theodor W. (Hrsg.) Spätkapitalismus oder Industriegesellschaft? Verhandlungen des 16. Deutschen Soziologentages in Frankfurt am Main 1968. Stuttgart: Ferdinand Enke, 1969, p. 117-138. Ad Carl Schmitt. Gegenstrebige Fügung. Berlin: Merve, 1987.

THOMPSON, E. P. A miséria da teoria ou um planetário de erros. Uma crítica ao pensamento de Althusser. Rio de Janeiro: Zahar, 1981.

TOLONE, Oreste. La 'posthistoire' di Arnold Gehlen. A cavallo tra modernità e postmodernità. Humanitas, v. 62, n. 2, 2007, p. 410-419.

TUCHOLSKY, Kurt. Gesammelte Werke, Bd. 5. Reinbek bei Hamburg: Rowohlt, 1975.

Unger, Nancy Mangabeira. Eclipse. In: UNGER, Nancy Mangabeira. $O$ encantamento do humano. Ecologia e espiritualidade. São Paulo: Loyola, 2000, p. 21-23.

WEBER, Max. A política como profissão e vocação. In: WEBER, Max. Escritos políticos. São Paulo: Martins Fontes, 2014, p. 389-463.

WEISS, Johannes. Kulturelle Kristallisation, post-histoire und Postmoderne. In: Vernunft und Vernichtung. Zur Philosophie und Soziologie der Moderne. Opladen: Westdeutscher Verlag, 1993, p. 169-179. 